\title{
Canadian provincial, territorial, and federal government aging policies: A systematic review
}

\author{
Donna Marie Wilson ${ }^{*}$, Jane Osei-Waree, Jessica Anne Hewitt, Andrew Broad
}

Faculty of Nursing, University of Alberta, Edmonton, Canada; ${ }^{*}$ Corresponding Author: donna.wilson@ualberta.ca

Received 3 July 2012; revised 5 August 2012; accepted 12 August 2012

\begin{abstract}
In most countries, population aging is becoming more evident now that the first members of the large babyboom cohort have reached 65 years of age. As an accelerating increase in the number of older persons and the proportion of the public aged 65 and older will now occur, planning for population aging has become ever more crucially important. A systematic review of Canadian provincial, territorial, and federal government documents was undertaken to search for the existence of population aging policies, and to determine the aims and other content of the most current policy documents. Documents were identified in all but two jurisdictions of Canada (two northern territories). Document developers, and the aims and content of the 14 reviewed documents varied considerably. Some similarities were identified, however, including some common stated purposes for these documents - to address current issues and challenges facing older people and to plan ahead for a preferred future with population aging.
\end{abstract}

Keywords: Canada; Systematic Review; Population Aging; Government Policy; Social Policy

\section{INTRODUCTION}

Population aging is becoming much more evident in Canada and most other countries, in large part because the first members of the large babyboom generation have begun to reach 65 years of age [1,2]. With nearly 1 in 3 Canadians or 10 million persons belonging to this cohort [2], it is not surprising that population aging has been the subject of considerable conjecture in Canada [3]. Over the next two decades, as this entire cohort reaches age 65, the proportion of Canadians who are considered "old" will increase from under $14 \%$ currently to over $20 \%$ [2]. Most other countries similarly can expect this increase in population proportion, accompanied by an increase in the num- ber of persons who not only reach old age but also often reach advanced old age [3,4]. Although some futurists are suggesting that the babyboom cohort is more likely to be healthy and to work past age 65 as compared to previous cohorts [1,5], much concern exists in general about the impact of an aging population on the social and economic welfare of the country [3,4,6-11]. This concern is not surprising, as health service utilization studies have consistently identified aging as a major factor in the need for and use of hospitals, nursing homes, home care and other health or supportive care services [12-21]. This evidence and other available information collected over the years, coupled with consistent and long-term fears about aging and population aging, should have engendered a wide range of plans and planning among the various policy-making and other groups. Governments at all levels are perhaps the most important in this regard, as they are charged with creating and implementing needed public policy.

The 2012 federal budget is the most recent illustration of the national government's response to population aging. Some significant future changes were announced for Canada's Old Age Security program, including an increase in age eligibility to 67 from 65 currently. Although government budgets are plans that help shape the future, they are not as visionary or directive as the policy documents that are created voluntarily by governments. At this point in time, with population aging accelerating now, it is important to determine if governments are prepared for or are becoming prepared through policy for population aging. Furthermore, if governments are preparing for population aging, it is important to determine which general directions or aims and specific strategies exist. A systematic review of Canadian provincial, territorial, and federal government policy documents was undertaken to assess for the presence of government policy documents in Canada and to critically evaluate the aims and other content of these policy documents.

\section{SYSTEMATIC REVIEW PROCESS}

Over the past decade, systematic reviews have become an important tool for summarizing and critiquing existing 
bodies of research evidence on specific topics or questions [22,23]. Many published systematic reviews, some identified however as "state of science" or "integrative literature" reviews, can now be found through library database searches. Although some differences exist in the processes or methods that are used to conduct the various types of reviews, such as whether qualitative research and other non-RCT articles will be sought and reviewed, most involve a careful search for all relevant articles and then an evaluation of their research quality followed by an assessment of the findings within the remaining articles [23]. Reports of systematic reviews typically provide information on the search and selection of articles for review, with this audit trail important for showing that a careful review was undertaken and there should therefore be some confidence in the findings that are presented, and also for enabling future replications [22].

As indicated above, a systematic search for and review of public policy on population aging in Canada was undertaken to address the question: What Canadian provincial, territorial, and federal government policy documents on population aging exist, and what is the content of the most current policy documents? Instead of the normal systematic search of library databases for published research articles, a search for online government documents was undertaken in 2011-12. Documents were sought through the Google and Yahoo search engines using the search terms: "population aging" combined with "policy," and then also the name of each jurisdiction (i.e. Government of Canada, etc.). A second search was conducted when no documents were found for two jurisdictions; this search used government department titles. Health department policy documents were first sought as healthcare system sustainability with population aging has been a long-standing concern in Canada. Social services and other department documents were then sought.

Initially, all documents identified were retained if they focused fully or partly on population aging. After these documents were read by team members, only the most current document or documents in each jurisdiction were retained. Only the most current ones were kept and reviewed as these illustrate the most recent concerns about and views on population aging, and also the expected actions from strategic plans of governments in relation to population aging. All but 2 of the 14 jurisdictions had one or two policy documents for review. Each document's stated reason or reasons for creation, and suggested actions or other strategies and recommendations for action were identified by one team member and summarized in Table 1. After this information was confirmed to be correct by all team members, a comparison of findings was undertaken by the team as a whole to consolidate and validate the findings. Following this, a report was drafted by one member of the team and approved after minor changes by the other team members.

\section{FINDINGS}

As shown in Table 1, 14 documents were reviewed (2 each for 2 jurisdictions and none for 2 jurisdictions). A wide range of authors was noted; including governments as a whole, a Special Senate Committee tasked with investigating population aging, a federal agency created and made responsible for public health in Canada, provincial health ministries, other provincial ministries or departments, and provincial advisory committees or secretariats with a mandate for seniors' care and/or other groups that include seniors. The development years also varied considerably; the oldest document by the Government of Northwest Territories' Department of Health and Social Services is dated 2002, and the most recent document by the Seniors and Healthy Aging Secretariat in the province of Manitoba is dated 2011. Of these 14 documents, $80 \%$ were created prior to 2010. Two were dated 2010 and one was dated 2011.

All documents had more than one aim or reason identified for their development. The stated reasons for the creation of these documents varied considerably, but with many similarities across them. Population aging was cited in all documents as the primary reason for development. The Special Senate on Aging [1] document, however, also indicated that advanced aging or aging among seniors was another reason for the document to be created for the federal government and then also other interested bodies or persons. Furthermore, in all documents, the need to address challenges and issues currently faced by senior citizens was identified as a factor for document development. In all but one document, multiple challenges and/ or issues with population aging were identified. One document alone had a narrow focus; it was designed to address the need to create "age-friendly" communities in Manitoba, communities where senior citizens would be better able to live easily and fully despite age-related disabilities [24]. One other document also had a limited scope, as this document was said to be created out of concern for two issues: 1) poverty and 2) social isolation among seniors living in the province of Quebec [25].

The identified need for greater home support so as to enable aging-in-place and also the related need for improved continuity or integration of services to better support seniors at home as they age were additional common creation factors (10/14 documents). In four documents, the need for greater support of wellness and healthy aging initiatives for enhanced wellness into advanced old age were also cited as creation factors. For instance, the document created by the British Columbia Ministry of Health [5] outlined four strategies to promote and support healthy living into and throughout old age. 
Table 1. Canadian population aging policy documents.

\section{CANADIAN FEDERAL GOVERNMENT}

Public Health Agency of Canada (2009) [3]

Special Senate Committee on Aging (2009) [1]
In 2009, population aging and aging among seniors was again recognized in Canada. The same vision, principles, and 1998 National Framework on Aging (NFA) were presented; with these affirming the prior framework on aging.
Tasked with a mandate to review public programs and services for seniors, identify gaps that exist in meeting the needs of an aging population, and make recommendations for service delivery in the future to address the challenge of an aging population, this final report by an appointed Senate Committee identifies issues impacting older persons and societal/government issues, and makes 5 recommendations:

1) Move immediately to take steps to promote active aging and healthy aging, and to combat ageism.

2) Provide leadership and coordination through initiatives such as a National Integrated Care Initiative, a National Caregiver Strategy, a National Pharmacare Program, and a federal transfer to address the needs of provinces with the highest proportion of the aging population.

3) Ensure the financial security of Canadians by addressing the needs of older workers, pension reform, and income security reform.

4) Facilitate the desire of Canadians to age in their place of choice with adequate housing, transportation, and integrated health and social care services.

5) Act immediately to implement changes for those populations groups for which the Federal Government has a specific direct service responsibility, and in relation to Canada's official language commitments.

\section{BRITISH COLUMBIA}

British Columbia Ministry of Health (2008) [5]
This framework, based on previous initiatives, focuses on four strategies:

1) Create age-friendly communities - plan for and support an aging population in all communities, by working with local government and other partners to promote and implement age-friendly practices in communities throughout British Columbia.

2) Mobilize and support volunteerism - increase the number of volunteers over age 65 through programs such as the Aging in Action campaign to increase volunteer opportunities and thus support older people's community participation and independence.

3) Promote healthy living -increase physical activity among people aged 50+, in part through partnerships with local governments, First Nations, seniors’ and community organizations for building ActNow BC Seniors' Community Parks.

4) Support older workers - give people age 55 + the opportunity to work with mandatory retirement and other workplace barriers eliminated. Also facilitate continued working through increased flexibility and choice in retirement planning by permitting pension plan members to accrue pension benefits until age 71 , and allowing $\mathrm{BC}$ registered pension plans to offer phased retirement benefits.

\section{ALBERTA}

Government of Alberta (2010) [34]
Population aging and increasing diversity among seniors has created "opportunities and a need to address challenges across a wide range of policy areas" (p. i). This framework defines and articulates the Government of Alberta's roles and responsibilities in "responding to the needs of an aging population. It is intended to provide clarity to other governments, sectors, stakeholders, and all Albertans about how the Government of Alberta intends to act in a number of key areas” (p. i). Based on 10 principles for consistent action, 8 strategic policy directions (with plans for each) are outlined:

1) Financial security and income-Albertans will have access to adequate financial resources to meet their needs in their senior years.

2) Housing and aging in the right place-Alberta seniors will be are able to reside in the place that is appropriate for their circumstances.

3) Continuing care-Alberta seniors will have access to a range of continuing care services that enable them to reside in an environment that is appropriate for their circumstances.

4) Health aging and health care-Alberta seniors will be supported in maintaining optimum health as they age.

5) Transportation and mobility-Albertans will have access to safe, affordable, appropriate, and accessible transportation options in their senior years.

6) Safety and security-Alberta seniors will be supported in maintaining optimum independence in making decisions about their lives and are free from abuse.

7) Supportive communities-Alberta seniors are engaged as full and welcome participants in their communities.

8) Access to government-Alberta seniors will be able to easily access Alberta government programs, services, and supports. 


\section{Continued}

SASKATCHEWAN

Provincial Advisory

Committee of Older Persons (2003) [35]
A statement with seven guiding principles (dignity, independence/self-determination, participation, fairness, safety and security, self-fulfillment, and recognition) and 6 goals was developed for the Government of Saskatchewan and society to work toward. This statement is "consistent with the shift to a wellness approach and ... the following vision: to protect and promote the health, dignity, and well-being of all older persons in Saskatchewan” (p. 4). Each goal has a list of recommendations for the Minister Responsible for Seniors to achieve the vision and goals. These recommendations (arising from discussions in 2001 and 2002) are to provide a foundation for the improvement of services to seniors in Saskatchewan (with services expected to change to reflect current priority concerns). Goals:

1) Ensure provision of and access to affordable and supportive housing and services for older persons.

2) Ensure the provision of safe and affordable transportation for older persons.

3) Ensure the access and availability to quality and appropriate health care services for all older persons. (includes medications, informal caregiving, and promoting healthy aging early in life as subcategories)

4) Promote active living and lifelong learning.

5) Enhance the recognition of contributions of older persons.

6) Enhance the safety and security of older persons.

\section{MANITOBA}

Seniors and Healthy Aging Secretariat (2011) [24]
Building on the 2005 Manitoba Council on Aging Act, a statement of mutual vision was developed for governments, organizations, and communities to work together toward a more Age-Friendly province. Seven principles are identified but with collective efforts to focus on 3 goals to facilitate older Manitobans to "realize their full potential to lead active, socially engaged, and independent lives” (p. 1). Goals:

1) Position Manitoba as an age-friendly leader which contributes fully to the global movement set-out by the WHO's Age-Friendly Projects and supports the full inclusion of citizens of all ages in their communities.

2) Encourage innovative strategies and methods throughout the province and at all levels, to more fully address and support the current, emerging and future needs, interests, and abilities of older Manitobans.

3) Assist in the development of communities that empower older Manitobans to lead active, socially engaged, and independent lives conducive to healthy aging.

ONTARIO

Ontario Ministry of Health and Long-Term Care (2007) [27]
A four-year strategy was developed because of population aging and the need to ensure "resources are available to assist those who wish to remain at home" (p. 1). This strategy is focused on expanding home care and community support services in the province's 14 Local Health Integration Networks (LHIN), where innovative projects are expected to support non-traditional partnerships or new preventative and wellness services that are locally developed and implemented. The province's 14 LHINs will receive funding to help deliver an integrated continuum of community-based services so seniors can stay healthy and live more independently in their homes. Not only is this strategy expected to improve the lives of Ontario seniors but also ensure the sustainability of the province's health system.

QUEBEC

Government du Quebec (2007) [36]
This action strategy (developed through the annual budgetary process and based upon the "reality: the elderly have never made up such a large proportion of our society, and that proportion is expected to increase in the years to come,” p. 5) outlines financially-supported and other initiatives oriented to 4 primary objectives:

1) Increase disposable income (split retirement income and increase tax credit for retirement income).

2) Promote home support (refundable tax credit for volunteers who assist informal caregivers, improved refundable tax credit for home support, free medication for low-income seniors, and tax credit for informal caregivers).

3) Adapt services and infrastructures (regional approach, and multiple possibilities).

4) Strengthen the place of the elderly in society (promote the right of the elderly to dignity and to the full exercise of their citizenship, promote the physical activity of seniors, promote phased retirement, and support seniors who want to invest in future generations).
Comité consultatif de lutte contre la pauvretéet l'exclusion sociale (2010) [25]
Concerns about equality and the economic plight of some citizens in the province led to a provincial statute that has created a group charged with enabling work toward a poverty free and more inclusive Québec. This group is empowered to advise the government on policies to impact on poverty and social exclusion, and also to monitor these policies. Aging alone and poverty in old age were identified as initial priority issues, with two major thrusts identified for subsequent action:

1) Improving the living conditions of single individuals age 45 and over who are in situations of poverty, and

2) Breaking the isolation of single individuals ageing in situations of poverty and social exclusion. 


\section{Continued}

\section{NEWFOUNDLAND AND LABRADOR}

Government of

Newfoundland and Labrador (2007) [37]
The Government of Newfoundland and Labrador embraced healthy aging, with outcomes expected in five years on 28 goals in six priority directions:

1) Recognition of older persons - through increased societal respect and regard for older persons; age-friendly policies, programs and services; and greater social inclusion of seniors in our society.

2) Celebrating diversity_-by ensuring that the diversity of the aging population is seen and valued in provincial policies, programs, and services.

3) Supportive communities - by enhancing the role that communities play to support an aging population.

4) Financial well-being - by improving the financial well-being of seniors through identification of opportunities; improving knowledge about government services and programs; and encouraging financial and retirement planning.

5) Health and well-being - by ensuring people as they age have the best possible physical, emotional, social, mental, and spiritual health and well-being.

6) Employment, education and research - by focusing on the impact of an aging population on employment, education, and research.

\section{NOVA SCOTIA}

Province of Nova Scotia (2005) [28]
Nine key areas of focus with population aging were identified for the province, with each having a broad goal and specific foci of attention for each:

1) Celebrating seniors: Nova Scotians value seniors and celebrate their lifelong contributions (eliminate ageism and acknowledge seniors' contributions to society).

2) Financial security: Secure and sufficient income that provides an adequate standard of living for older Nova Scotians (lifelong financial planning and sustainability of assistance programs).

3) Health and well-being: A range of supports and services to enable seniors to optimize their health and well-being (health promotion, disease and injury prevention, health services and continuum of care, and quality health, services for seniors, research \& education).

4) Maximizing independence: Seniors enjoy maximum independence with support from family, friends, community, and government (in-home services, family caregivers, paid care providers, and community supports).

5) Housing options: Affordable, accessible, safe, and supportive housing options are available to seniors (affordable housing options, and housing planning and design)

6) Transportation: Affordable, safe, and accessible transportation options are available to seniors (affordable, accessible transportation, driver licensing, rural and urban needs, and pedestrian safety and falls prevention).

7) Respecting diversity: Nova Scotians recognize, respect and respond positively to seniors in all their diversity (cultural diversity, gender equity, social inclusion, and diversity in information and services).

8) Employment and life transitions: Workplaces support and encourage the participation, health, lifelong learning and volunteer activities of older workers.

9) Supportive communities: Seniors have opportunities for personal growth, lifelong learning, and community participation in safe and supportive environments.

NEW BRUNSWICK

An information collection process in the province identified population aging as a concern and the issue that "society is faced with a major challenge in providing adequate publicly-funded long-term care to seniors" (p. 7). Five themes are outlined in a strategy for seniors that is based on a vision and values, each with various goals to focus subsequent action:

1) Informal caregivers: Goal 1.1: increase supports to families, friends and volunteers to help them care for their seniors. Goal 1.2: reduce burden on family members providing care for their loved ones.

2) Formal caregivers: Goal 2.1: improve recruitment and retention of formal caregivers. Goal 2.2: improve training of formal caregivers.

3) Affordability and sustainability: Goal: reduce need for long-term care services.

4) Quality of service delivery: Goal 4.1: increase the efficiency and effectiveness in the delivery of long-term care services. Goal 4.2: increase the community's capacity to provide informal services to its citizens. Goal 4.3: improve assessment quality.

5) Quality of care. Goal 5.1: increase the range of options to manage care at home. Goal 5.2: increase the choice of residential options for seniors. Goal 5.3: increase availability of services for clients with dementia and other mental health needs. Goal 5.4: increase the accountability of services.

PRINCE EDWARD ISLAND

A strategy was developed out of a growing awareness of population aging and increased chronic illness, a changing healthcare system, the need to promote and support healthy aging, the need for integration of services, and the need to provide "seniors with the care they need" (p. 4). To support healthy aging, through immediate and long-term actions, 5 pillars of focus were outlined:

1) Manor and nursing home replacement.

Prince Edward Island Department of Health (2009) [26]
2) Palliative home care drug pilot project.

3) Enhanced home care.

4) Expanded and improved long-term nursing home care.

5) Transitional care for persons waiting placement in a nursing home. 


\section{Continued}

YUKON TERRITORY—no documents

NORTHWEST TERRITORIES

This plan follows a review of programming for seniors that was guided by three principles: (a) fairness and equal treatment to all seniors in government programming, (b) access to government programs that are harmonized across departments, and

(c) fiscal sustainability of seniors programs. A May, 2002 report entitled: Review of Programs and Services for Seniors resulted in 28 recommendations and expected actions, divided into five key areas:

1) A voice for seniors, with 3 actions: Seniors' forum, review of programs and services, and community participation.

Government of Northwest Territories', Department of Health and Social Services (2002) [29]

2) Integration/coordination of programs, with 3 actions: Organization and administration of programs, coordination at the community level, and departmental coordination.

3) Improving programs, with 12 actions: Income assessment, standardized age of eligibility, consolidation of income support programs, inflation, adequacy of income, seniors' home heating subsidy, independent living and housing needs, housing repair and maintenance, continuing care framework, extended health benefits, employment, transportation, communication and information, and seniors' database.

4) Informing seniors and the public, with 5 actions: Elder abuse, seniors-friendly workshops, retirement planning, consolidation of toll free lines, and volunteerism.

5) Research and policy development, with 3 actions: Research, program principles, and policy framework.

NUNAVUT—-no documents

Less often, such as in two documents, the issue of increasing rates of chronic illness in old age was cited as a creation factor $[1,26]$. Two other documents focused in part on fiscal matters, as they cited sustainability of the healthcare system as an issue of concern that had led to document creation $[27,28]$. Another document identified a need for fiscally-sound seniors' services [29]. One document was unique in that it indicated a changing healthcare system, one with fewer inpatient hospitalizations and more ambulatory services, was necessitating a multipronged strategy for ill and dependent older persons [26]. In another case, a policy document was developed to affirm a previous policy document and to extend progress on the initiatives presented in that 1998 document-this being Canada's National Framework on Aging [3].

The suggested action strategies and/or recommendations for change in the 14 documents varied considerably, in part because each document was designed to address different issues or aspects of population aging. Twelve of the documents contained many diverse strategies and wideranging recommendations, while two focused their recommendations narrowly on distinct issues, notably: 1) poverty and social isolation in aging [25] and 2) the need for age-friendly communities [24]. Among the many different action strategies or change recommendations in these 14 documents, the most common were focused on ways to enhance, enable, or encourage active and healthy aging (8/14 documents). The next most common type focused on financial security for older persons (7/14 documents), and continuing care improvements such as through the enhanced integration of services for seniors (7/14 documents). Recommendations for the respectful recognition and inclusion of seniors in society were also common (6/14 documents), followed by specific recommendations to enable or support aging-in-place (5/14 docu- ments).

Less common action strategies and recommendations were also present, although most of these ones were identified in more than one document. Four documents contained recommendations to address the needs of aging workers and also to encourage or enable working later in life. Four documents had recommendations to assist mobility or transportation of seniors. Four had recommendations to reduce or eliminate elder abuse, and one of these also broadly addressed safety needs of senior citizens. Four had recommendations to ensure or secure appropriate housing for seniors, including nursing homes for those needing this type of housing. Three documents contained recommendations to support autonomy and decision-making by seniors. Three addressed the needs of specific groups such as those who were vulnerable because of being poor, socially isolated, and/or a minority group member. Two documents contained recommendations to combat ageism. Two had recommendations to encourage and support volunteerism by seniors. Two contained recommendations to help seniors gain access to existing services within the province.

\section{DISCUSSION}

This review of Canadian government documents was helpful for showing that most governments in Canada are not only aware of population aging, but developing strategies designed to address issues and help bring about a preferred future with older persons and a larger proportion of the population aged $65+$. This government awareness is also not new; only one of the 14 reviewed policy documents was created in 2011, the year that the first babyboom generation members began to reach age 65. It is also notable that the most current Public Health Agency 
of Canada's [3] national policy document dated 2009 was designed in part to affirm the previously developed $\mathrm{Na}$ tional Framework on Aging for Canada. This 1998 framework was created after the Federal, Provincial and Territorial Ministers Responsible for Seniors recommended in 1994 that it be developed to respond to the needs of older persons, as they viewed them as a unique demographic group that was rapidly growing in number [30]. In 2009, the Special Senate Committee on Aging similarly indicated in their document that they had been charged with reviewing the 1998 National Framework on Aging, as well as Canada's role and obligations in light of the 2002 Madrid International Plan of Action on Ageing [1]. They also were to examine the issue of aging in our society, and assess current public programs and services in Canada compared to strategies for population aging in other countries. As such, it is apparent that the federal government and most other governments in Canada have been planning for population aging for some time. This conclusion suggests that the impact or outcomes of these current and previous policy documents can and should be studied in the future. They could have been extensively implemented and have had considerable impact, or they could have been theoretical only and so have had little practical application.

As indicated above, no policy documents were identified in two jurisdictions. Both of these are in northern Canada where the proportion of the public aged 65 and older is much smaller than in other regions of Canada [2]. It is understandable then that these jurisdictions would not be as motivated to create policy on population aging. The historic involvement of the federal government in northern affairs could have also resulted in a greater reliance there on federal government policy. It is also possible that these two northern governments are addressing population aging through other means. According to Leslie Pal [31], a public policy expert, governments are less often using public policy and legislation to govern, but instead are relying on other public or private measures to address emerging or evident public needs and issues.

Another major finding was the widely varying authors of these policy documents. Few documents were developed directly by a government. More often, an organization was developed or enabled to undertake this work. This finding is also in keeping with Pal's [31] assertion that governments are increasingly creating or using existing non-government bodies to provide advice on public needs and issues. As governments were not the author of most reviewed documents, and although the reviewed documents were all considered to be high quality, it is of considerable concern that few of these organizations have continued to exist after the reviewed policy document was developed. Few then could help to ensure the application of the recommended policy actions or strategies, and assist in measuring or monitoring the impact or outcomes of them.
The Senate Committee on Aging is a prime example. As this group is no longer in evidence, their excellent wideranging policy document could now languish as an instrument for change.

The reasons presented for document creation were particularly revealing. Although many different reasons were cited, the two reasons that appeared in all documents are critical for discussion: 1 ) population aging was occurring and 2) the need to address challenges and issues currently faced by senior citizens. These two reasons suggest a benign but reactive approach as population aging has been evident for decades, and so it is unfortunate the older persons living today in Canada have challenges and issues to contend with. Regardless of this concern about reactivity, these documents could have instead identified population aging as a problem with negative implications for Canadian society. These documents could have focused on reducing the challenges and issues for non-seniors arising from the growing number of older persons. A much more positive approach was evident instead, and in fairness, it should be recognized that it would be impossible to prevent all challenges and issues for seniors in advance of rapid and substantial population aging. It is also possible that much progress has already been made, and so the issues and challenges facing seniors now are less problematic than if no prior work had been undertaken.

It is also important to consider the symbolic value of these documents. The stated reasons for creating these documents are together highly commendable, as they demonstrate a wide ranging consideration of socially-relevant needs and issues. For instance, the identified needs to create age-friendly communities, address poverty and social isolation among seniors, enable aging-in-place, improve continuity or integration of services to better support seniors as they age, and for greater support of wellness and healthy aging initiatives to enhance wellness into advanced old age indicate much interest in ensuring Canada is a positive place to live and a successful society overall. In addition, these documents show important policy bodies exist or can be readily created - ones that are evidently well informed on the needs of older persons as well as the broad socially-responsible implications of population aging for Canada.

As identified above, the suggested action strategies and/or change recommendations in the 14 documents varied considerably. This variance is understandable, as each document was designed to address different issues or aspects of population aging. Most documents contained many diverse recommendations, but with considerable overlap across them indicating considerable synergy in thinking and thus relatively similar action strategies and/or recommendations across Canada. Although some policy documents focused narrowly on poverty and social isolation in aging [25] or the need for age-friendly communities 
[24], the recommendations to address these issues were relatively similar to the recommendations in other documents, such as those that focused on enabling work (paid and volunteer) in later life. The most common action strategies and/or recommendations are also of note. The most common were focused on ways to enhance, enable, or encourage active aging and healthy aging (8/14 documents), ensure financial security for older persons (7/14 documents), and enhance integration of services for seniors (7/14 documents). Ways to increase respectful recognition and inclusion of seniors in society (6/14 documents), and recommendations to enable or support aging-in-place (5/14 documents) were additional common strategies across multiple documents. Although commendable, progress reports are now needed. Some are already emerging, such as the 2009 Province of New Brunswick's progress report [32] on the 2008 New Brunswick seniors' independence support strategy [33]. The 2009 report indicates considerable progress was made in one year. This rapid progress is commendable and perhaps entirely possible because a clear and compelling policy document was developed. As such, a number of advantages to developing and having policy documents on hand were evident, including the impetus and directed efforts arising from recognized issues or needs and action plans [34-37]. These advantages appear to have been recognized outside of Canada, as many other countries have developed population aging policy documents to similarly focus attention and efforts [38,39]. The biggest disadvantage of the Canadian documents at this point in time appears to a lack of follow-up information on whether the action strategies or recommended changes were implemented and what the impacts or outcomes of the implemented ones have been. Evaluation studies are thus indicated.

\section{CONCLUSION}

With population aging becoming more evident in Canada, as the large babyboom generation is now aging, a systematic review was undertaken to determine if governments across Canada are prepared for or are becoming prepared for a much larger number of older persons and a major increase in the proportion of the public that is age 65 and older. This search for provincial, territorial, and federal government documents established the presence of population aging policy and thus an official awareness of population aging in all jurisdictions except two northern ones. Clearly, for some time now, most Canadian governments have recognized population aging as a matter for public policy. The policy purpose and action content varied considerably across the existing policy documents, although most were designed to address current issues and challenges faced by seniors, and to guide action toward a preferred future with population aging. As population aging continues, it will be increasingly important to deter- mine if these policy plans for population aging are being carried out and what their impacts or outcomes are.

\section{REFERENCES}

[1] Special Senate Committee on Aging (2009) Canada's aging population: Seizing the opportunity. Final report. http://www.parl.gc.ca/Content/SEN/Committee/402/agei/ rep/AgingFinalReport-e.pdf

[2] Statistics Canada (2011) Population projections: Canada, the provinces and territories, 2009 to 2036.

http://www.statcan.gc.ca/daily-quotidien/100526/dq1005 26b-eng.htm

[3] Public Health Agency of Canada (2009) 1. Introduction. http://www.phac-aspc.gc.ca/seniors-aines/publications/pr o/healthy-sante/nfa-cnv/nfa_-cnv1-eng.php

[4] World Health Organization and Public Health Agency of Canada (2005) Preventing chronic diseases. A vital investment.

http://www.who.int/chp/chronic_disease_report/part1/en/i ndex.htm

[5] British Columbia Ministry of Health (2008) Seniors in British Columbia: A healthy living framework.

http://www.health.gov.bc.ca/seniors/pdf/seniors_framewo rk_web.pdf

[6] Canadian Institute for Health Information (2011) Multiple chronic conditions, not age, main driver of health system by seniors.

http://www.cihi.ca/CIHI-ext-portal/internet/en/Document/ types+of+care/primary+health/RELEASE_27JAN11

[7] Gilmour, H. and Park, J. (2006) Dependency, chronic conditions and pain in seniors. Health Reports, 16, S21S31.

[8] Goetghebeur, M.M., Forrest, S. and Hay, J.W. (2003) Understanding the underlying drivers of inpatient cost growth: A literature review. American Journal of Managed Care, 9, S3-S12.

[9] Ko, Y. and Coons, S.J. (2005) An examination of selfreported chronic conditions and health status in the 2001 Medicare Health Outcomes Survey. Current Medical Research \& Opinion, 21, 1801-1808.

[10] Nugent, R. (2008) Chronic diseases in developing countries. Annals of the New York Academy of Sciences, 1136, 70-79. doi:10.1196/annals.1425.027

[11] Ohinmaa, A., Schopflocher, D., Jacobs, P., et al. (2006) A population-based analysis of health behaviors, chronic diseases and associated costs. Chronic Diseases in Canada, 27, 17-24.

[12] Cranswick, K. (1998) Who needs short-term help? Canadian Social Trends, 50, 11-15.

[13] Forbes, D.A., Stewart, N., Morgan, D., et al. (2003) Individual determinants of home-care nursing and housework assistance. Canadian Journal of Nursing Research, 35, 15-36.

[14] Health Canada (1999). Provincial and territorial home care program: A synthesis for Canada. Minister of Public Works and Government Services, Ottawa. 
[15] McBride, T., Morton, A., Nichols, A., et al. (2011) Comparing the costs of alternative models of end-of-life care. Journal of Palliative Care, 27, 126-133.

[16] Sheps, S.B., Reid, R.J., Barer, M.L., et al. (2000) Hospital downsizing and trends in health care use among elderly people in British Columbia. Canadian Medical Association Journal, 163, 397-401.

[17] Stuart, M. and Weinrich, M. (2001) Home- and community-based long-term care: Lessons from Denmark. Gerontologist, 41, 474-480. doi:10.1093/geront/41.4.474

[18] Van Houtven, C.H., Oddone, E.Z., and Weinberger, M. (2010) Informal and formal care infrastructure and perceived need for caregiver training for frail US veterans referred to home and community-based services. Chronic Illness, 6, 57-66. doi:10.1177/1742395309352694

[19] Wilson, D.M. and Truman, C.D. (2005) Comparing the health services utilization of long-term-care residents, home-care recipients, and the well elderly. Canadian Journal of Nursing Research, 37, 138-154.

[20] Wilson, D., Truman, C., Huang, J., et al. (2005) The possibilities and realities of home care. Canadian Journal of Public Health, 96, 385-389.

[21] Wilson, D.M., Birch, S., Cohen, J., et al. (2011) Home care developments in the Canadian province of Alberta with regionalization. Global Journal of Health Science, 3, 3-8. doi:10.5539/gjhs.v3n1p3

[22] Stevens, K.R. (2001) Systematic reviews: The heart of evidence-based practice. AACN Clinical Issues, 12, 529538. doi:10.1097/00044067-200111000-00009

[23] Whiting, L.S. (2009) Systematic review protocols: An introduction. Nurse Researcher, 17, 34-43.

[24] Seniors and Healthy Aging Secretariat (2011) Age-friendly Manitoba charter. http://www.gov.mb.ca/shas/agefriendly/charter.pdf

[25] Comité Consultatif de Lutte Contre la Pauvreté et l'Exclusion Sociale (2010) Ageing alone: The impact of poverty and social exclusion. Building a future in which every individual can grow old with dignity. http://www.cclp.gouv.qc.ca/index_en.asp

[26] Prince Edward Island Department of Health (2009) Prince Edward Island's healthy aging strategy. http://www.gov.pe.ca/photos/original/doh_agingstrat.pdf

[27] Ontario Ministry of Health and Long-Term Care (2007) Ontario's aging at home strategy. http://www.health.gov.on.ca/en/public/programs/ltc/33_o ntario_strategy.aspx
[28] Province of Nova Scotia (2005) Strategy for positive aging in Nova Scotia.

http://www.gov.ns.ca/seniors/pub/2005_StrategyPositive Aging.pdf

[29] Government of Northwest Territories (2002) Seniors' action plan 2002-2003: Response to the review of programs and services for seniors.

http://www.hlthss.gov.nt.ca/pdf/reports/seniors/2002/engli sh/seniors_action_plan.pdf

[30] Health Canada (1998). Principles of the national framework on aging: A policy guide. Division of Aging and Seniors, Health Canada, Ottawa.

[31] Pal, L.A. (2010) Beyond policy analysis: Public issue management in turbulent times. Nelson Education, Toronto.

[32] Province of New Brunswick (2009) Being there for seniors: Our progress in long-term care. http://www.gnb.ca/0182/pdf/LongTermCare-e.pdf

[33] Department of Social Development (2008) Be independent longer: New Brunswick’s long-term care strategy, 2008. http://www2.gnb.ca/content/dam/gnb/Departments/sd-ds/ pdf/LTC/LongTermCareStrategy-e.pdf

[34] Government of Alberta (2010) Aging population policy framework.

http://www.seniors.alberta.ca/seniors/agingpopulation/fra mework/

[35] Provincial Advisory Committee of Older Persons (2003) Saskatchewan's provincial policy framework and action plan for older seniors.

http://www.health.gov.sk.ca/action-plan-for-older-persons

[36] Government du Quebec (2007) Action strategy for the elderly, budget 2007-2008.

http://www.budget.finances.gouv.qc.ca/budget/2007-2008 /en/pdf/Aines.pdf

[37] Government of Newfoundland and Labrador (2007) Provincial healthy aging policy framework. http://www.releases.gov.nl.ca/releases/2007/health/0711n 04HA\%20Policy\%20Framework.pdf

[38] United Nations Secretariat (2000) Expert group meeting on population ageing and population decline. http://www.un.org/esa/population/publications/popdecline /popdecline.htm

[39] Centre for Policy on Ageing (2012) Policies on ageing. http://www.cpa.org.uk/cpa/policies_on_ageing.html 